REVISTA CHILENA DE LITERATURA

Noviembre 2009, Número 75, 217 - 232

\title{
LA ESCRITURA DE LAS IMÁGENES: DE $E L$ RECOPILADOR (1836) AL FACUNDO (1845)
}

\author{
Hernán Pas \\ Universidad Nacional de La Plata - CONICET \\ hernan_pas@yahoo.com
}

RESUMEN / ABSTRACT

El presente trabajo se centra en el estudio de El Recopilador, periódico publicado en Buenos Aires en 1836, en relación con los tópicos discursivos del romanticismo literario y con la formación de una tradición literaria nacional en la primera mitad del siglo XIX en el Río de la Plata. La lectura de El Recopilador permite calibrar con más precisión algunos de las figuras retóricas -el paralelismo entre mundo árabe y mundo gaucho, por ejemplo- que serán explotadas ampliamente por los letrados criollos, principalmente por Sarmiento en su Facundo. Civilización o Barbarie.

Palabras Clave: El Recopilador, romanticismo literario, Río de la Plata, letrados criollos.

This work presents a study of El Recopilador, a Buenos Aires journal published in 1836. The analysis is thus focused on the discursive topics of literary romanticism and the formation of a literary national tradition during the first half of 19th-Century in Argentina. The reading of El Recopilador permits to recognize with more precision some rhetorical figures -for example, the parallelism between the gaucho and the Arabian worlds- that will be largely utilized for creoles lettered, mainly by Sarmiento's Facundo. Civilización o Barbarie.

KEY WORDS: El Recopilador, Literary Romanticism, Río de la Plata, literate criollos. 
"El centro del saber, en los siglos XVII y XVIII, es el cuadro" Michel Foucault. Las palabras y las cosas

"En la pampa, los únicos que escriben son los viajeros ingleses" Ricardo Piglia. Crítica y ficción

Entre las páginas de la biografía que Ricardo Rojas dedicó a Sarmiento hay una discusión sobre el saber, el poder que ese saber establecido configura y la pretendida legitimidad de la comunidad científica internacional. No es una discusión que involucre la pericia letrada del sujeto biografiado ni el estatuto literario de un texto como el Facundo que, por otra parte, desde su perspectiva integracionista, Rojas estimaba menos que Educación popular... Es una discusión sobre el territorio. Específicamente sobre el territorio denominado "Patagonia". Pero lo que se discute no es la nominación sino el hecho de que hasta no muchos años antes ese territorio seguía apareciendo en los mapas mundiales como res nullius. Y Rojas aprovecha para contar lo que en Archipiélago, nos dice, ya había contado: en 1934, mientras era trasladado como confinado político en un buque nacional pudo comprobar que el viaje se realizaba con las cartografías inglesas en las que el país ( $\mathrm{Ar}$ gentine Confederation) "aparece separado de Patagonia, tierra de nadie..." (Rojas 356).

Sobre el territorio, sobre las miradas que sobre ese territorio se habían fraguado y otra vez sobre las pretensiones científicas de señeras figuras como la de Darwin también discutían varias décadas atrás los miembros de la comisión científica que acompañaron al General Roca en la denominada "conquista del desierto". Retóricamente ofuscado, Manuel de Olascoaga consignaba en su diario la tergiversación realizada por el naturalista inglés al haber hablado de la pampa cuando en realidad solo había cruzado de Patagones a Bahía Blanca. Ese mismo recorrido "que sirvió de criterio a de Moussy y otros poetas - dice allí- ofrece la vista de un llano inalterable sin un árbol y sin la menor curva en el horizonte". Y agrega: "escribieron, por descontado, tomando de esas únicas fuentes" (Doering y Lorentz 151).

Refractarias de la intrincada relación que mantuvieron a lo largo del siglo ambos propósitos pero ostensiblemente exponenciales de la nueva función de las letras que ellas representan, la queja de Rojas -que se extiende a la Geografía Universal de Gregoire (París, 1887)-así como la rectificación del comisionado roquista de la imagen heredada de la pampa como "un llano 
inalterable" vienen a subrayar el sentido más explícito de la fórmula de Pigila, según la cual los únicos que escribieron en la pampa argentina fueron los viajeros ingleses. Entre los trabajos dedicados a esa cuestión, Adolfo Prieto (1996) ha señalado la visible deuda que esos relatos mantienen con Viaje a las regiones equinocciales del Nuevo Continente, de Alexander von Humboldt, de cuyas páginas extrajeron varias imágenes que sirvieron para describir tópicamente el escenario pampeano. En efecto, tanto para autorizarse (la mayoría de las veces), como para tomar distancia del modelo, las narraciones de los viajeros ingleses producidas aun en una segunda etapa expeditiva se inscriben en la exitosa operación textual que el naturalista germano había elaborado a partir de sus Cuadros ${ }^{1}$. En el uso de las imágenes consagradas por la prosa de Humboldt se hallan varias extrapolaciones que, de modo sorprendente, configuran un sedimento simbólico-discursivo que desempeñará un rol fundamental en el imaginario letrado rioplatense -la imagen de la pampa como un océano es quizá una de sus proyecciones más evidentes ${ }^{2}$. Pero lo que requiere atención aquí no es tanto el recurso a una forma de autoridad discursiva -digamos, el uso excesivo o anómalo que esas escrituras ejercen citando al modelo- sino el tipo de descripción que esa retórica implica. Porque en ese modelo de configuración textual, el carácter exótico del objeto "retratado" suponía, al mismo tiempo, la idea de una singularidad cultural que no solo podía ser recuperada por medio de la escritura, sino incluso creada por ella. Los cuadros de ese relativismo cultural funcionaban así como formas de codificación de un saber letrado sobre la propia identidad criolla; identidad que si, por un lado, se construía

1 Las firmas más destacadas de esa segunda etapa expeditiva son las de Francis Bon Head, Joseph Andrews y Edmond Temple, cuyos respectivos relatos elaboraron una imagen del país de gran incidencia en la imagen que empezaban a proyectar los letrados románticos locales. Head, F. B. Rough Notes Taken During Some Rapid journeys Across the Pampas and Among the Andes, de 1826, y Reports on the Failure of the Rio de la Plata Mining Association, de 1827; Andrews, J. Journey from Buenos Ayres Throught the Provinces of Cordova, Tucuman, and Salta to Potosí..., de 1827; Temple, E. Travels in various Parts of Perú. Including a Year's Residence in Potosí, de 1833

2 Las sugerencias de esa "apropiación" están en la base del estudio de Prieto (1996). Como se sabe, el territorio del Río de la Plata no fue recorrido por la expedición de Humboldt y Bonpland. En relación al tópico paisajístico de la "pampa como un mar", Silvestri (233 y ss.) ha destacado recientemente, antes que los escritos humboldtianos, la función de las cartografías inglesas. 
apelando deliberadamente a esa cadena intertextual de usos y citas, por el otro, suponía la reproducción de los valores implícitos que la retórica de esa cadena textual ponía en circulación. El otro sentido de la frase de Piglia, aquel que refiere indirectamente al tipo de operación letrada que los escritores criollos ejercieron apelando a las estampas de esa retórica consagrada, es el que organiza los argumentos de las páginas que siguen.

\section{EXOTISMO Y REPRESENTACIÓN}

Quizá sea en las páginas del semanario ilustrado El Recopilador-continuidad de El Museo Americano (1835)-, publicado en Buenos Aires en 1836, donde esa operación se desarrolla por primera vez de manera razonada. Entre las características sobresalientes del periódico porteño, cuyo redactor principal fue Juan María Gutiérrez, hay que destacar la presencia de imágenes litográficas que acompañan cada número como complemento de su empresa editorial, además de la variada gama de temas, todos de orden "cultural", desarrollados en sus páginas ${ }^{3}$. En el número 16, bajo el título de "El Recopilador a sus suscriptores", se aclara el eclecticismo de la publicación mediante la idea de una necesaria educación de "muchas noticias, ideas y nociones tan exactas como necesarias", y se resume la propuesta de los redactores

3 Quizá también sea El Recopilador el primer periódico ilustrado en el que el lenguaje visual cumpla una función comunicativa preponderante, combinado a su vez con un incipiente programa estético criollo que, si bien no se declaraba editorialmente, otorgaba un rasgo distintivo en relación con su antecedente inmediato, El Museo Americano. Las litografías que acompañaban cada número del semanario - a cada lámina correspondía un artículo temático- mostraban el impulso universalista de la empresa editorial. Las imágenes litográficas - del conocido grabador César Hipólito Bacle- condensaban así el saber ilustrado al hacer concurrir en las páginas del semanario imágenes no solo de distintas regiones del mundo sino de disímil carácter iconográfico, acompañadas por un artículo descriptivo. Así, si en el n ${ }^{\circ} 1$ se destaca una "Historia del vapor. Aplicado a la navegación", y en el n 11 aparece la historia sobre la "Fabricación del papel", el n ${ }^{\circ} 2$ muestra un cuadro en la que se ven, en medio de un bosque cenagoso, una serie de habitantes lugareños en zancos ("Habitantes de Las Landas") y el n ${ }^{\circ} 10$ porta una litografía sobre los "Juegos de los antiguos mexicanos", donde se narran y se describen las fiestas populares indígenas cuyos participantes son llamados "voladores". Esta variada gama de "representaciones" mediante imágenes, que va desde los progresos de la industria hasta las costumbres exóticas de diversas regiones, escenifica una operación en la que debe inscribirse el tipo de apercepción romántica que incluye al propio territorio, como intentaré argumentar en el cuerpo del trabajo. 
bajo un adagio latino que une al deleite la necesaria utilidad de las lecturas (Omne tulit punctum, qui miscuit utili dulci, Lectorem delectando) ${ }^{4}$. Bajo el imperio de esa utilidad que debe acompañar toda lectura en la Buenos Aires post-independentista, la empresa del semanario incluye la descripción de lugares y sociedades desconocidas, cuyo carácter de extrañeza buscan "retratar" las representaciones litográficas que las acompañan. Voy a recurrir deliberadamente a un fragmento de esas descripciones para iluminar algunas de las características prominentes de ese programa:

Si sus habitaciones y andrajos repugnan y repelen, no por eso tema nada el viajero que se extravíe en aquel páramo, pues hallará allí más hospitalidad y sincero desinterés que en los demás puntos ricos y civilizados [del Departamento]. (El Recopilador, N² 2, pág. 10, col. 2).

Cualquiera que haya abrevado en el intertexto formado por los relatos de viaje extranjeros y los ensayos iniciales de la llamada "generación romántica" argentina -entre los cuales las Cartas de Echeverría resultan un ejemplo privilegiado- no dudaría en asimilar a este pasaje la referencia a las "sencillas y hospitalarias" "chozas" -así como a las virtudes- de los gauchos argentinos. Sin embargo, este fragmento pertenece a un artículo sobre "Los habitantes de Las Landas", una región francesa ubicada entre "el río Adus y la ciudad de Burdeos", y cuya lámina litográfica "representa -dicen los redactores- a los habitantes de los páramos de la Gascoña, vestidos con el traje singular que les es propio, que en vano se buscaría en algún otro lugar del mundo"7. El significado de singularidad y extrañeza se liga a lo lejano, a la no conocido, y remite sobre todo al tópico romántico del exotismo como

4 El Recopilador, $\mathrm{n}^{\circ} 16$, pp. 121-123, cols. 1 y 2.

5 Con el rótulo de "generación romántica" refiero al grupo de escritores que la crítica ha identificado bajo el nombre de "generación del 37", sin dejar de llamar la atención sobre lo problemático que resulta el uso de la categoría de 'romanticismo' para designar una estética de raigambre europea y sus usos o reconversiones por parte de los letrados criollos latinoamericanos.

6 Cito de las Cartas a un amigo, de Echeverría (404).

7 El Recopilador, ${ }^{\circ}{ }^{\circ}$, pág. 9, col. 1. El subrayado me pertenece. 
particularidad cultural que, como acabamos de ver, es propio de una región, un pueblo o una nación ${ }^{8}$.

En ese contexto debe destacarse el espacio que el semanario dedicó a las piezas poéticas de Echeverría así como a los ensayos encargados de orientar la nueva producción literaria de la región ${ }^{9}$. Entre ellos sobresale el ensayo "El caballo, en la provincia de Buenos Aires", presumiblemente escrito por el propio Gutiérrez, cuya publicación se inició en la tercera entrega y cuya conclusión apareció recién en su número veintidós. Con la intención de reflexionar acerca de "cuál es la parte de originalidad que debemos nosotros ya civilizados [en oposición a los aborígenes], al uso hábil y frecuente que sabemos hacer de las nobles condiciones del caballo" (El Recopilador, $\mathrm{N}^{\circ}$ 3 , pág. 17 , cols. 1 y 2), el articulista dedicaba sendos pasajes a describir las costumbres y los hábitos de la población rural, enfatizando la mutua dependencia entre paisano y caballo. Esa dependencia cobra en el ensayo el carácter de una contigüidad que se extiende de manera metonímica hasta identificar a la población rural con el espacio natural que ella habita:

El movimiento del caballo despierta la meditación e impone silencio al ginete: las ideas se suceden con la rapidez del galope; pero los labios se niegan a espresarlas, tal vez porque la excesiva actividad como el profundo reposo producen iguales efectos. ¿No podría explicarse por esta observación, el carácter silencioso de nuestra campaña y la especie de pereza que tienen para espresar lo que piensan y sienten? (El Recopilador, $\mathrm{n}^{\circ}$ 3, pp. 18 y 19, cols. 1 y 2 ).

8 En el marco de ese programa entre romántico e ilustrado lo exótico es también lo original, lo pintoresco. Cabe recordar aquí que lo pintoresco (palabra de origen italiano, y que designa "un punto de vista propio de los pintores") tuvo su elaboración teórica en Inglaterra en la segunda mitad del XVIII (elaboración que en cierto sentido anticipa a la estética del romanticismo) y se liga a uno de los significados con que en Francia fue concebido en sus inicios el término Romantic, proveniente, como lo pittoresque, de Inglaterra. Ver al respecto la Introducción de Mario Praz (1999 [1976]: 33-61).

9 El Recopilador (1836) dio a luz en su primer número la "Apología del matambre" de Esteban Echeverría, así como el poema "Serenata" del mismo autor (pieza que también aparece en las Cartas a un amigo, dato que quizá permita estipular con más precisión la fecha de redacción de las mismas), recogido luego en el volumen Rimas (1837). Además de otros poemas del mismo autor, el semanario dedicó extensos artículos (como "La poesía y la Música", El Recopilador, n ${ }^{\circ}$, pág. 125) a comentar y analizar las nuevas producciones poéticas de Buenos Aires. 
Esa relación de contigüidad aparece, además, codificada literariamente mediante la cita shakespeareana -"A horse! a horse! my kingdom for a hor$s e$ !"- que porta como acápite el ensayo y que, como se sabe, llegará a las páginas del Facundo en su traducción francesa. Pero en el orden descriptivo, la identificación entre bestia y "paisano" excede la retórica erudita en un movimiento que naturaliza el objeto "retratado" y lo coloca por fuera de la escritura y, por lo tanto, por fuera del lugar de enunciación que al principio dibujaba, ambiguamente, un "nosotros" genérico. Así, a diferencia de las modas que rigen los usos de la vestimenta en las ciudades, en los campos, dice el articulista:

La ley de la necesidad dictó las formas del trage, y tal cual es y ha sido, permanecerá mientras el hombre identificado con el caballo necesite soltura en los miembros y agilidad en los movimientos. Lo que decimos del vestido puede aplicarse a los hábitos morales, a las pasiones del ánimo y al desenvolvimiento y cultura de los sentidos y de la inteligencia (El Recopilador, $\mathrm{N}^{\circ}$ 3, pág. 18, col. 1).

Como se ve, el ensayo de Gutiérrez puede leerse como el incipiente bosquejo de un programa literario del nativismo criollo. Es necesario, sin embargo, inscribir el artículo en el contexto de la propuesta del semanario para delinear los posibles alcances de ese programa. En este sentido, como se ha dicho, es prominente en las páginas de la publicación la presencia de imágenes y artículos dedicados a culturas extrañas o desconocidas, como el caso del pueblo francés citado más arriba. Resulta sugerente, por lo mismo, la cantidad de artículos o reseñas que El Recopilador dedica a los países asiáticos, como Siria o Turquía, entre otros, con el fin de ofrecer, como se dice acerca de Japón, "algunos rasgos característicos de la fisonomía de aquellos pueblos cuyos usos y costumbres son del todo distintos de las naciones para nosotros más conocidas" ${ }^{10}$. Lo que esas páginas ponen en circulación, sin embargo, es un modo de representación en el que imagen y palabra se complementan ofreciendo una descripción estereotípica. Una litografía que reproduce una

10 Transcribo la serie de artículos e imágenes litográficas dedicados a oriente: "Las ruinas de Palmira" ( $\left.\mathrm{n}^{\circ} 8\right)$; "Cuerpo de guardia turco en Esmirna" ( $\mathrm{n}^{\circ}$ 9); "Los gemelos siameses" $\left(\mathrm{n}^{\circ} 13\right)$; "Las Petimetras de Japón" (n 15); "Tipou-Saib" (n²0); "Las costumbres de las islas Noukahiva" $\left(n^{\circ} 24\right)$. 
pintura original de M. Deschamps, por ejemplo, sobre un "Cuerpo de guardia turco", incita a los redactores al comentario siguiente:

Nada mejor, que una serie de cuadros de esta especie, para dar una idea exacta de las costumbres de un país: representadas por un medio que tanto se acerca a la naturaleza, y hace tan viva impresión en los sentidos, se recibe una instrucción más exacta y duradera, que con la lectura de las descripciones de viajeros, por muy prolijas que estas sean (El Recopilador, $\mathrm{N}^{\circ}$ 9, p. 71, col. 1).

Este comentario no impide sin embargo a los redactores la recurrencia constante de esos mismos relatos que describen desde una perspectiva europea dichas costumbres. Dirán en este mismo artículo: "M. Mac Farlane, que visitó la Turquía asiática en 1828 da interesantes pormenores, acerca de los progresos que allí se han introducido con respecto a la parte militar" (El Recopilador, $\mathrm{N}^{\circ}$ 9, pág. 71, col. 2). El artículo, como es previsible, reproduce la perspectiva irónica sobre los intentos por parte de los generales franceses de domesticar a las milicias nativas: "los turcos aprenden con mucha dificultad a llevar el paso", dirá. El modo de representación se liga entonces a un formato codificado por la literatura europea pero del que no son ajenas otras manifestaciones artísticas, como la pintura o los grabados. Ese régimen mimético - que coincidía con el auge del romanticismo europeo a principios de siglo- otorgaba además un sentido particular a lo exótico, categoría con la cual el incipiente relativismo cultural podía describir los rasgos peculiares de un pueblo, al mismo tiempo que los definía en relación con valores provenientes de su propia mirada. Esa noción, típicamente romántica, fue reelaborada o reapropiada por los letrados criollos frente a la necesidad de construir una tradición diferenciada de la colonia. Porque si bien el repertorio de esa literatura de viaje proveía las imágenes y los sentidos de un territorio todavía desconocido, la elite letrada criolla seleccionó las estampas que mejor se avenían a la necesidad de establecer los rasgos propios de un primitivismo cultural que consagrara al mismo tiempo origen (cultural) y originalidad (estética). Entre ellas, las dedicadas a describir el espacio geográfico o los rasgos tipológicos que pudieran portar los habitantes rurales, pues en ellos se centraba la identidad criolla que empezaba a configurarse en la progresiva diferenciación de las nuevas repúblicas. De esas estampas sobresale -por su amplia repercusión entre los letrados del Río de la Plata- el relato del capitán Francis Bond Head, Rough Notes Taken During Some Rapid 
Journeys Across the Pampas and Among the Andes, publicado en volumen en Londres en 1826.

Gutiérrez remite a ese intertexto cuando, sobre el final de su ensayo, indica que, como observaba el viajero inglés, "el gaucho en su pampa no es menos sagaz que Zadig; Zadig el oriental que se lleva la palma y la gloria del sabio" (El Recopilador, $\mathrm{N}^{\circ} 22$, pág. 172, col. 2). La mención de la obra de Voltaire, Zadig o el destino (1747), proviene en realidad de la reseña que el periódico Le Globe hizo del libro de Head poco después de su publicación, y es una buena muestra del modo mediado de lectura en el que ese intertexto se configura ${ }^{11}$. Habría que agregar, además, que la apelación de Gutiérrez a la obra francesa -antes que al propio relato del inglés a quien supuestamente cita- no parece del todo fortuita ${ }^{12}$.

En sus notas sobre la pampa, F. B. Head, al detenerse en describir la vida de sus "rústicos" habitantes, había subrayado la condición pre-moderna y, por lo tanto, históricamente dislocada, del gaucho. "Es cierto-escribió- que el gaucho no tiene lujos, pero el gran rasgo de su carácter es su falta de

11 Es en esa reseña francesa donde aparece la referencia a la novela de Voltaire, y no en el libro del viajero inglés. Una reedición de dicha reseña aparece en la nueva traducción de las Rough Notes que realizaron recientemente P. Fontana y C. Román (187-204). Es evidente que no solo abrevaron en esa versión Sarmiento y Echeverría, como bien sostienen Fontana y Román, sino que era un texto conocido por varios de sus pares letrados; así lo indica, por lo menos, el ensayo de J. M. Gutiérrez.

12 En efecto, la mención al personaje de la nouvelle de Voltaire la introduce el reseñista de Le Globe en relación con una nota en la que Head discurre brevemente sobre el modo que tienen los gauchos de "descifrar las pisadas de los caballos" (véase la edición de Fontana y Román [2007], pp. 146 y 197). El motivo inmediato de esa relación se halla en el capítulo 3 del relato de Voltaire, en donde Zadig es capaz, sin haber visto, de reconocer y describir con exactitud a la perra y al caballo de los reyes por los rastros que dejaron en el suelo. Ahora bien, en el ensayo de Gutiérrez esa relación es ampliada a "ciertas observaciones ingeniosas" de los gauchos: "ellos dirán, por ejemplo: por aquel bajo va un hombre -y va a todo galope- $¿$ Cómo lo saben, si entre el lugar que señalan y el que ocupan, se interpone una altura? -Lo saben por los pájaros que se levantan del bañado y huyen atemorizados. Dirán también: en aquel matorral hay un animal muerto, y también lo saben por el grito o el vuelo de las aves de rapiña que se disputan los despojos del cadáver" (El Recopilador, pág. 171, col. 2). La mediación del intertexto europeo señala así una construcción ampliamente explotada por los letrados rioplatenses, cuyo caso paradigmático se consolidará casi una década más tarde en la prosa de Sarmiento: la analogía entre el mundo árabe y el mundo gaucho. 
necesidades" (Head 32) ${ }^{13}$. El viajero inglés, maravillado por la falta de interés pecuniario en la mentalidad gaucha, no había dudado en decretar la desaparición de esas costumbres en manos del progreso: "Un individuo humilde que vive solitario en la llanura sin fin, no puede introducir en las vastas regiones deshabitadas que lo rodean, artes o ciencias" (Head 32). El gaucho, entonces, podía permanecer allí, como la misma pampa, "hasta que la población, que creará necesidades, invente los medios de satisfacerlas" (Head 32).

Lo que en el viajero inglés es descripción exotista o, si se prefiere, modulada por un horizonte de lectura europeo, en el ensayo de Gutiérrez se transforma en una sutil operación letrada capaz de convertir en "hábitat natural" un territorio y, al mismo tiempo, en motivo literario la naturalización de las costumbres que ejerce el ensayo al identificarlas con la naturaleza que se describe. Su escritura enmarca lo particular en un cuadro cuyo sentido connota rigidez e inmutabilidad -"nuestros paisanos - dirá en su ensayo-que son sobre el caballo como hechos de una misma pieza, un mismo tronco, una estatua ecuestre" (El Recopilador, $\mathrm{n}^{\circ} 22$, pág. 172, col. 1)-al mismo tiempo que diseña el tópico romántico del primitivismo cultural, al trasvasar las propiedades animales al orden físico y moral de los gauchos, o "paisanos", a quienes describe como "hombres salidos de manos de la naturaleza" ( $E l$ Recopilador, $\mathrm{N}^{\circ} 22$, pág. 173, col. 2). En esa traza que va del viajero inglés al ensayista criollo se inscribe el otro sentido de la fórmula de Piglia. La categórica dislocación temporal del gaucho -quien, según el viajero inglés, "brinda poco servicio a la gran causa de la civilización, que es deber de todo ser racional promover (Head 47)-, es la materia maleable con la cual erigir una tradición: su irracionalidad se convierte, en la prosa ilustrada de Gutiérrez, en propiedad naturalizada cuya particularidad, como "la nutria, las plumas de avestruz" o "la sal mineral", puede ser sublime -es decir, poetizable-porque en esa escritura modélica se la representa como un producto atávico de la tierra cuya originalidad radica, precisamente, en su primitivismo cultural: "si quieres conservar tu gracia y tu belleza -dice Gutiérrez-, y despertar ideas y sentimientos poéticos, no dejes el campo por el estrecho pesebre de las ciudades" (El Recopilador, $\mathrm{n}^{\circ}$ 3, pág. 18, col. 1). Mediante una escritura que

13 La traducción de Fontana y Román es casi la misma: "Es verdad que el gaucho no tiene lujos, pero el principal rasgo de su carácter es que es un ser sin necesidades" (47). 
busca retratar las "escenas nacionales", como se advierte en el ensayo, Gutiérrez parecería reproducir un tópico paisajístico (pintoresco) consagrado por el romanticismo: es en el campo donde el gaucho convoca la efusión poética pues allí se da la impresión del cuadro, la común armonía entre individuo y territorio, entre cultura y naturaleza. Y, de hecho, Gutiérrez reproduce dicho tópico. Pero hace, además, otra cosa. Porque la exhortación del pasaje que acabo de citar no está dirigida al gaucho, sino al caballo ${ }^{14}$.

\section{CUADROS, TÓPICOS Y ESTEREOTIPOS: RECONSIDERACIONES SOBRE EL USO DEL IMAGINARIO ORIENTALISTA EN EL FACUNDO DE SARMIENTO}

Es indudable, por otra parte, la regencia de algunas "notas" de F. B. Head en el Facundo, de Sarmiento. Claro que la misma supera ampliamente el sistema de citas que puebla los capítulos de la biografía del sanjuanino. Empezando por la errónea atribución al capitán inglés, en el primer capítulo, de una frase que pertenece en realidad a Humboldt, hasta recalar en aquella que encabeza precisamente el capítulo en el que se discurre sobre el tipo de asociación rural, se comprueba que el intertexto funciona como autoridad y matriz descriptiva, que, por supuesto, el texto del sanjuanino expande de manera particular. En relación con la condición premoderna subrayada por Head, Sarmiento dirá: “[El gaucho]: es fuerte, altivo, enérjico. Sin ninguna instrucción, sin necesitarla tampoco, sin medios de subsistencia como sin necesidades, es feliz en medio de su pobreza i de sus privaciones" (Sarmiento 40, subrayado mío).

Pero la reproducción y expansión de esa citas que demuestran el funcionamiento del intertexto, quisiera sostener aquí, va más allá del carácter apelativo del mismo o de su fundamento meramente retórico. Sarmiento lee en el capitán inglés esa condición premoderna y anticapitalista del gaucho de las pampas argentinas de manera tal que la "barbarie" que allí sitúa es ya un pasado proyectivo de la identidad criolla. La lectura capitalista del viajero inglés ("es cierto que podría hacer queso y venderlo por dinero", dice), es decir,

14 El pasaje continúa así: “... y sobre todo no permitas que se suba a tus espaldas el que surca los mares y os maltrata por falta de destreza en gobernar las bridas" (El Recopilador, $\mathrm{N}^{\circ}$ 3, pág. 18, col. 1). 
específicamente moderna y nacionalista, aclara el régimen de lectura sobre la realidad social de los campos argentinos que ciñe las páginas del Facundo. Si la ausencia de civilización, de la civitas y, por supuesto, del mercado y de la economía que "distribuye" los bienes de uso y permite refinar las costumbres, es una muestra categórica de un vacio en la historia de esas formaciones societales, llenarlo significa para los criollos rioplatenses como Sarmiento transformar esa carencia en principio de actividad productiva. Queda, sin embargo, un resto que es necesario apresurarse a "pintar", pues allí reside el material de una "verdadera identidad criolla": el epos, "que el infeliz [el "gaucho cantor"] despliega en sus rapsodias ingenuas" (Sarmiento 54).

Entre el amplio espectro de descripciones que el sanjuanino dedica al gaucho -en el que se destacan, por supuesto, los "cuadros" del segundo capítulo- quiero traer aquí una frase que nos reenvía al ensayo de Gutiérrez. Dice Sarmiento: "El caballo es una parte integrante del argentino de los campos; es para él lo que la corbata para los que viven en el seno de las ciudades" (58). El sustrato esencial de esta frase se aproxima más al tipo de descripción realizada por el articulista de El Recopilador-donde paisano y caballo son "como hechos de una misma pieza"- que al tópico exotista de la literatura de viaje. Además, los sintagmas de la frase sarmientina estructuran una oposición arquetípica cuyo sentido absoluto encuentra en la cita orientalista, a la que recurre en ese mismo parágrafo, su fundamento retórico: "aquí vuelve a aparecer la vida árabe, tártara. Las siguientes palabras de Victor Hugo parecen escritas en la pampa: 'No podría combatir a pie; no hace sino una sola persona con su caballo: Vive a caballo; trata, compra i vende a caballo..." etc.

El recurso a las equivalencias o el uso que hace el sanjuanino del sistema analógico es un rasgo común compartido por la escritura de la época y aparece, por ejemplo, en el mismo relato del viajero inglés a quien Sarmiento cita (comparaciones, por ejemplo, entre la "choza" del gaucho y la del "high-lander" escocés). Ricardo Piglia ha hecho una lectura sagaz del uso de la analogía por parte de Sarmiento: "la lógica de las equivalencias -dice Piglia- disuelve las diferencias y resuelve, mágicamente, las contradicciones" (16). El fundamento ideológico del Facundo, entonces, disuelve las disimetrías. Piglia dirá: "Si se compara lo conocido con lo desconocido (...) es porque lo desconocido (Oriente, África, Argelia) ya ha sido juzgado y definido por el pensamiento europeo" (17). En esa "definición” podemos reconocer la construcción de un visión orientalista que operó como un dispositivo de hegemonía cultural -lo que Edward Said definió como “orientalismo 
moderno"- que erigió "la idea de una identidad europea superior a todos los pueblos y culturas no europeos" (Said 26) ${ }^{15}$.

Ahora bien, como sostiene Altamirano (1997), la imaginería orientalista en el Facundo está estrechamente vinculada a la constelación de nociones e imágenes que componían el tema del despotismo en esa época, cuya articulación conceptual remite a El espíritu de las leyes (1748), de Montesquieu. La especificidad de un uso funcional del archivo orientalista no parece contravenir sin embargo el hecho de que uno de los procedimientos retóricos del romanticismo se asociaba a una serie de estereotipos ideológicos. Lo que habría que subrayar aquí es que casi diez años antes de que Sarmiento comenzara a publicar su texto por entregas, esos estereotipos ideológicos operaban en el modo de representación literaria de la elite letrada rioplatense ${ }^{16}$. Porque no es la mención de la nouvelle de Voltaire -relato que, por supuesto, se inscribe en la visión orientalista que señala Said- sino el tipo

15 Una de las fuerzas que actuaban en la construcción de esa visión, nos dice Said, era, precisamente, la analogía: "Mahoma era para el islam lo que Cristo para el cristianismo". A partir de esa analogía -entre otras- se formó "un círculo cerrado que nunca fue roto por una exteriorización de la imaginación (...) El concepto cristiano del islam era integral y autosuficiente" (87).

16 Recordemos que ya en la Memoria descriptiva del Tucumán (1834), de Alberdi, el pensamiento de Montesquieu y sobre todo su noción de "despotismo" son retomados en la "sección" del ensayo que lleva por título "Carácter físico y moral del pueblo tucumano bajo la influencia del clima" (título que anticipa, por supuesto, la mención al "aspecto físico" del primer capítulo del Facundo). Alberdi intentaba demostrar por entonces que el "clima" selvático de Tucumán no ejercía influencias negativas en la población y terminaba contradiciendo y negando los asertos del racionalista francés. Sin embargo, terminaban por avalar la influencia climática y geográfica y diseñaba dos grandes categorías sociales (los temperamentos "biliosos y melancólicos") que definían, a su vez, caracteres reconocibles en los distintos estratos. "Una de las conclusiones que se siguen de estas observaciones -escribe Alberdi- es que el plebeyo tucumano es más apto para la guerra y el distinguido para las artes y las ciencias" (Alberdi 24). Notable conclusión del joven letrado quien, consciente de esa distinción, no podría dejar de prever que los lectores de su ensayo reconocerían en su propia escritura "las plumas melancólicas de Mme. Staël, Chateaubriand, Hugo, Lamartine”. Desde una perspectiva típicamente romántica, Alberdi sostenía que esos hombres (los plebeyos) estaban propensos siempre "a las grandes virtudes o grandes crímenes", y remataba diciendo: "o es hombre sublime o peligroso" (Alberdi 23). Sublime o peligroso, el genio melancólico se hace sentir en la sociedad plebeya de Tucumán, esa forma indirecta de hablar de la república. Las "clases rústicas" a las que hace referencia la Memoria, muestran que "sus cantos y versos rudos, todavía están, sin embargo, envueltos en una eterna melancolía” (Alberdi 26). La rusticidad social que destaca Alberdi tiene un paralelo en las formas culturales de un esteticismo tan precario 
de representación que ejecuta Gutiérrez en su ensayo sobre la pampa, el que explota un régimen mimético afín a los cuadros que reproducen las páginas del semanario. Es en ese régimen mimético de exterioridad, estructuralmente similar al realismo -cuyos "cuadros" descriptivos, como señala Ramos para el Facundo, confirman la voluntad racionalizadora de esa escritura, así como los láminas litográficas se acercan para los redactores de El Recopilador a lo "natural"- donde la cita orientalista puede ser pensada como algo más que un uso retórico de una imaginería estereotípica.

Es mediante ese régimen mimético -que engloba lo circunstancial que pueda haber en el libro del racionalista francés ${ }^{17}$ - que el historicismo pudo pensar la historia como "la lucha recíproca que sostienen los que quieren detener el progreso con los que quieren desatar los lazos que le impiden volar sin obstáculo sobre las alas de la libertad" (López 28-29). La Memoria de las que son extraídas estas palabras -que mucho le deben al espiritualismo hegeliano a través de sus herederos franceses- probablemente alguna influencia tuvo en el esquematismo historicista del Facundo. La idea de una "ley del progreso continuo" en la que "los pueblos centrales del Asia son la familia primitiva del género humano" (López 30 y 39) presupone una economía temporal históricamente constituida que, a nivel discursivo, explota una retórica estereotípica en la representación del otro ${ }^{18}$. En ese esquema, el gaucho, que, según escribió Head, carece de "ciencias y artes", redime su letargo improductivo y atávico cediéndolo a "la causa de la civilización" que en letras de molde sabrá fijar la originalidad de su "gracia" y "belleza" -entre otras cosas, sus premodernas dotes arábigas- con la misma fidelidad

como arcaico que hace tempranamente de esos "cantos rudos" un símil de las propiedades naturales del territorio.

17 Basta un breve repaso del texto de Montesquieu para ver que las obras de las que se sirve para dar forma a su idea del mal político absoluto se inscriben en lo que Said llama orientalismo. Algunas de las más notables son: Ricault, Del Imperio otomano; Bernier, Sobre el Mogol y Viajes; La Loubere, Relación de Siam; Aristóteles, Política. (Cfr. Montesquieu 1950).

18 La productividad del estereotipo -su régimen de verdad- radica en ser un modo de representación que somete lo particular (la diferencia) a un discurso normalizador. "El estereotipo no es una simplificación por ser una falsa representación de una realidad dada. Es una simplificación porque es una forma fijada, detenida, de representación que al denegar el juego de la diferencia (que la negación a través del Otro permite) constituye un problema para la representación del sujeto en significaciones de relaciones psíquicas y sociales” (Bhabha 75 [la traducción es mía]). 
mimética que los redactores del semanario porteño atribuían a los cuadros que sus litografías reproducían.

\section{BIBLIOGRAFÍA}

Alberdi, Juan Bautista. "Memoria descriptiva sobre Tucumán”. Obras Selectas. Tomo III. 1834. Buenos Aires: La Facultad, 1920.

Altamirano, Carlos. "El orientalismo y la idea del despotismo en el Facundo". En Altamirano, C. y Beatriz Sarlo. Ensayos Argentinos. De Sarmiento a la vanguardia. Buenos Aires: Ariel, 1997. 83-102.

Batticuore, G., Klaus, G., y J. Myers. Resonancias románticas. Ensayos sobre historia de la cultura argentina (1820-1890). Buenos Aires: Eudeba, 2005.

Bhabha, H. K. "The other question. Stereotype, discrimination and discourse of colonialism". The location of culture. London and New York: Routledge, 1994. 66-84.

Doering, Adolfo y Pablo G. Lorentz. La conquista del desierto. Diario de los miembros de la Comisión Científica de la expedición de 1879. Buenos Aires: Comisión Nacional Monumento al Teniente General Julio A. Roca, 1939.

Echeverría, Esteban. Obras completas. Buenos Aires: Antonio Zamora, 1972.

El Recopilador. Museo Americano. Buenos Aires: 1836.

Head, Francis Bond. La pampa y los Andes. 1826. Buenos Aires: Hyspamérica, 1920.

Apuntes tomados durante algunos viajes rápidos por las pampas y entre los Andes. 1826. Traducción, Estudio preliminar y Notas de Patricio Fontana y Claudia Román. Buenos Aires: Santiago Arcos Editor, 2007.

Humboldt, Alexander. Tableaux de la nature. 1814. Traduite par CH. Galusry, Tome Premier. Paris: Gide et J. Baudry, Libraires-Éditeurs, 1851.

López, Vicente Fidel. Memoria sobre los resultados generales con que los pueblos antiguos han contribuido a la civilización de la humanidad. 1845. Buenos Aires: Nova, 1943.

Montesquieu. “De L'Esprit des Loix”. Euvres Complètes de Montesquieu. 1748. Paris: Société Les Belles Lettres, 1950.

Piglia, Ricardo. "Notas sobre Facundo". Punto de Vista. 3/8 (1980): 15-18.

Praz, Mario. La carne, la muerte y el diablo en la literatura romántica. Trad. Rubén Mettini. Barcelona: El Acantilado, 1999.

Prieto, Adolfo. Los viajeros ingleses y la emergencia de la literatura argentina, 1820-1850. Buenos Aires: Sudamericana, 1996.

Ramos, Julio. Desencuentros de la modernidad en América Latina. Literatura y política en el siglo XIX. México: FCE, 1989.

Rojas, Ricardo. El profeta de la pampa. $2^{\text {a }}$ ed. Buenos Aires: Losada, 1948.

Said, Edward W. Orientalismo. Madrid: Libertarias, 1990. 
Sarmiento, Domingo F. Facundo. 1845. Prólogo y notas del profesor Alberto Palcos. Reedición ampliada de la edición crítica y documentada que publicó la Universidad de La Plata, Buenos Aires: Ediciones Culturales Argentinas, 1961.

Silvestri, Graciela. "Errante en torno de los objetos miro. Relaciones entre artes y ciencias de descripción territorial en el siglo XIX rioplatense”. En Batticuore, G., Klaus, G., y Myers, J. 2005: 225-243. 